\title{
De que forma
}

Renan do Espírito Santo Tobias Duarte ${ }^{1}$ Erika Alvarez Inforsato ${ }^{2}$

toda gente tem que não ter cabimento para crescer Arnaldo Antunes (2003)

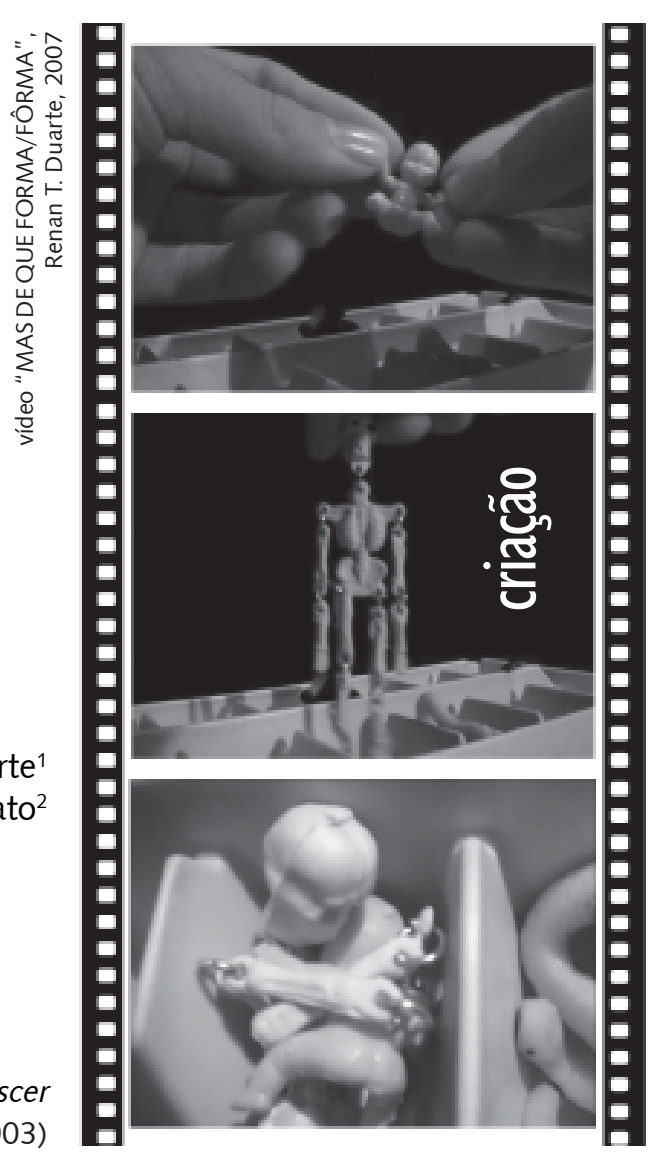

Películas desdobraram-se ao final de quatro meses de feitura de um diário de campo. Pele em forma de imagem filmada. Um assombro para quem acompanhou o processo; um lugar de expressão para quem o produziu.

Em meio a encontros e compromissos profissionais de um dos estágios do curso de graduação em Terapia Ocupacional da USP ("T.O. e as ações na interface arte e saúde", sob coordenação da Profa. Dra. Eliane Dias de Castro) - fez-se o salto. Em sua duração, experiências em projetos relacionados ao Laboratório de Estudos e Pesquisa Arte, Corpo e Terapia Ocupacional da FMUSP, por meio de seu projeto didático-assistencial - PACTO (Programa Composições Artísticas e Terapia Ocupacional), e de seus acordos de colaboração e parcerias com projetos externos à universidade, delineia-se um cenário de estágio no qual, junto aos profissionais, os estudantes tensionam e favorecem aberturas nos espaços e equipamentos de artes e cultura da cidade, para que recebam também as populações tradicionalmente restritas às redes de saúde. Com isto, vivenciam-se alguns enfrentamentos dos processos de homogeneização das diferenças e atua-se produzindo deslizamentos em relação às tendências históricas e culturais de institucionalização e desvalorização, que enfraquecem a vida de muitos. Esta proposta de trabalho, na interface da terapia ocupacional e artes potencializa o deslocamento da clínica para um campo de invenção e produção de novos agenciamentos - para técnicos, estudantes e participantes dos projetos -, numa aposta de que novas sociabilidades e formas de resistência possam ser engendradas (Lima et al., 2009).

No rastro dessa paisagem, as imagens aqui apresentadas em filme e fotografias sinalizam traços de uma sensibilidade constelada nas circunstâncias cursivas da graduação, descritas acima, somadas a um evento extraordinário: a ocupação da reitoria, realizada por estudantes da USP no primeiro semestre de 2007, que atravessou de forma contundente todo o processo de estágio daquele semestre. Uma experiência comum, que envolveu docentes, técnicos, estudantes e comunidade não-acadêmica de maneiras diferentes, com distâncias e aproximações conflituosas e convergentes.

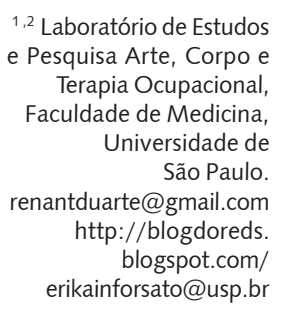

1,2 Laboratório de Estudos e Pesquisa Arte, Corpo e Terapia Ocupacional, Faculdade de Medicina, Universidade de São Paulo. renantduarte@gmail.com http://blogdoreds. blogspot.com/ erikainforsato@usp.br 
Vertigem é o estado intensíssimo que sentimos diante de um abismo, numa altura desmedida, quando nos defrontamos com uma distância assustadora. Vertigem é a distância traduzida em atordoamento, uma quantidade (de espaço) transformada em qualidade (intensiva), uma separação nos estirando por dentro e em direção ao exterior.

(Pelbart, 1989, p.123)

Pirotécnico e espetaculoso. Talvez. E intenso, consistente e pertinente em sua proliferação e prospecção ao que pode advir. Também. Esse filme, se surpreende seu espectador, é por tratar-se de um achado igualmente inusitado para o seu próprio autor. Num momento de vertigem da experiência coletiva, em que se experimenta a força e a fragilidade em sua radicalidade: a ideia da forma. Da forma de gelo.

No programa da disciplina, entregue aos estagiários, aparece pela primeira vez uma explicação do que seria o diário de campo, no item que descreve os trabalhos obrigatórios do estágio: "experiência singular do estágio - descrições, colagens, pensamentos, elaborações" (Castro, Inforsato, 2007, p.5).

No mesmo programa, o item "Orientações para a preparação do Diário de Campo" oferece algumas pistas:

O Diário de Campo deverá apresentar-se como um registro do período em que se dá o percurso do estágio, e as sensações serão o ponto de partida, com o objetivo de construção de um território com várias teias, suficiente para dar consistência às experiências vividas neste momento da vida de cada estagiário.

Por sensações vamos considerar aquilo que está relacionado aos órgãos do sentido (visões, toques, cheiros, audições, sabores) bem como o que consiste os lugares de pensamento (espécies de habitats, aquilo que faz proliferar o pensamento, que dá condições aos achados do pensamento) em vivências diretas do estágio e outras que a elas possam associar-se de modo livre e atemporal. A proposta é de que se constituam camadas, justaposições, aquém e além das ligações de interconexão.

Cada Diário de campo será desenvolvido em continuidade e nele deverão constar: descrições das situações de estágio; citações, referências, grafismos, pinturas, colagens, cópias, fotos, dobras, texturas etc que mantenham algum tipo de relação com as vivências do estágio; elaborações, associações e comentários que apresentem sua expansão e crescimento profissional na avaliação e proposição de saídas diante das vivências do estágio. (Castro, Inforsato, 2007, p. 7)

Assim os estudantes entram em contato com a proposta, acrescida de leves comentários da supervisora que os acompanha. O diário de campo deve ser entregue em quatro etapas e uma parte da carga horária do estágio reserva-se para essa produção. A cada entrega ocorrem interlocuções em que a supervisora faz uma apreciação crítica, considerando aspectos estéticos e educativos: "dificuldades", pontos duros, e potenciais a serem intensificados em experimentações/criações.

A experiência do Diário de Campo em um estágio de Terapia Ocupacional se mostrou uma estratégia capaz de conectar ética, estética e política, potencializando ações no campo da clínica, do cuidado e acompanhamento de pessoas, já que, em seu fomento à potência criadora, possibilitou inventar novos modos de intervir, de agir nas situações e com as pessoas, construção de novos territórios existenciais. A flexibilidade da proposta e das linguagens do diário permitiu uma plasticidade desse registro de vida, e portanto da própria produção da vida. O Diário de Campo se transforma em um Território Existencial, onde as marcas dos acontecimentos podem habitar, desenvolver-se e produzir novas marcas, novos modos de existir e criar. (Duarte, 2008, p.134)

Este experimento audiovisual assim surgiu. Em sua apresentação para a disciplina de estágio, era um conjunto de vídeos em que a sensibilidade ganhava expressão na convergência do estudante, seus 
3 Acesse o vídeo em Interface v.15, n.39, out./dez. 2011, no site da revista: www.scielo.br/icse ou www.interface.org.br percursos, da matéria que se deformava na luz, do som. A experiência de processar, observar e refletir traduzia-se num filmar, gravar, enquadrar, editar. $\mathrm{O}$ vivido ganhava pele, epiderme, película. Pele na qual se processavam experiências, onde sangravam e cicatrizavam-se atravessamentos. Pele que respirava e transpirava afetos. Pele a ser cortada, editada, explorada, enxertada.

Filmar era uma exploração cirúrgica dos territórios existenciais em que se podia, simultaneamente, mapear suas formas - conforme neles se vivia -, e deformá-los para que de outros modos nele se pudesse viver. Editando a vida numa espécie de cinemática do movimento, das posturas, dos corpos. Transposição cinematográfica do vivido.

[...] quando a gente escreve ou pinta ou canta a gente transgride uma lei. Não sei se é a lei do silêncio que deve ser mantido diante das coisas sacrossantas e diabólicas. Não sei se é essa a lei que é transgredida. (Lispector, 1999, p.150)

Cada vídeo continha um tema, um fio condutor, um disparador que norteava e enredava sua existência. Um deles: "MAS DE QUE FORMA/FÔRMA" ${ }^{3}$. Uma brincadeira séria, um tanto perturbadora. Jogando com a palavra "forma", seus significados e disparamentos. Em suas incursões, as imagens aglutinam-se em explosões e transbordamentos raivosos, que indiciam a experiência de formar-se profissionalizar-se, sobretudo -, com seus constrangimentos e condenações justapostos as suas promessas e encantamentos.

Quantos seres sou eu para buscar sempre de outro ser que me habita as realidades das contradições? Quantas alegrias e dores meu corpo se abrindo como uma gigantesca couve-flor ofereceu ao outro ser que está secreto dentro do meu eu? Dentro de minha barriga mora um pássaro, dentro do meu peito mora um leão. Este passeia pra lá e pra cá incessantemente. A ave grasna, esperneia e é sacrificada. O ovo continua a envolvê-la, como mortalha, mas já é o começo do outro pássaro que nasce imediatamente após a morte. Nem chega a haver intervalo. É o festim da vida e da morte entrelaçadas. (Clark apud Rolnik, 1996)

Há uma literalidade que, se num primeiro momento parece ilustrativa/ representativa, ao acompanhar seu desenrolar, uma espécie de "virar do avesso" se dá, e a crítica emerge da assunção do estereótipo, do clichê em seu extremo. Denúncia de si e do mundo, como operação clínica eficaz, em que a produção desta película é um esforço em fazer caber aquilo que transborda a capacidade de viver junto, com cada personagem que, no decorrer de um período de estágio em T.O., oferece proximidade - sejam participantes dos projetos, sejam professores, profissionais, familiares, autores, instituições etc.

\footnotetext{
"Não cabe..."

"Você tem que caber!"

"Isso não tem cabimento!"

"Durma bem"

"Comer, comer, comer..."
} 
Como?

A subjetividade humana e sua potência/capacidade de criação tornaram-se reféns do capital, moldadas e formatadas segundo seu interesse. A existência humana está aprisionada em padrões de desejo, consumo, sexualidade que ditam seus gestos e movimentos.

Como pensar uma formação que não seja uma formatação, rígida, e na qual não se achatem as diferenças, o singular, permitindo ao desejo assumir formas para manifestar-se, expressar-se?

Como fazer caber o estranho? O fora da norma?

Como permitir a deformação numa sociedade onde é cada vez mais valorizado o cabimento e o encaixe?

Como permitir que mesmo as peças que não encaixam participem da vida-quebra-cabeça?

Será necessário inventar novas formas, novos moldes que contemplem a diversidade?

(Criar novas peles, películas. Comer.)

AUTOR. - Eu queria poder "curá-la" de si própria, Mas sua - "doença? É mais forte que

meu poder, sua doença é a forma de sua vida. (Lispector, 1999, p.52)

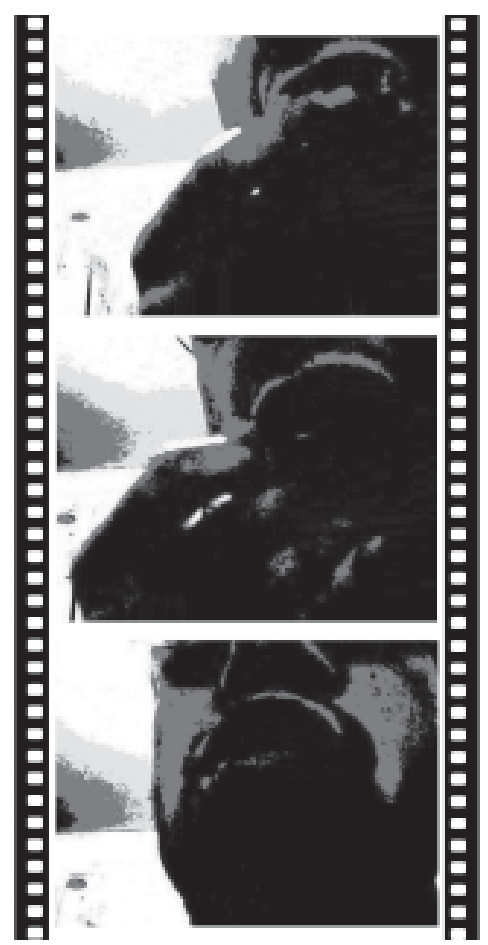

vídeo "MAS DE QUE FORMA/FÔRMA", Renan T. Duarte, 2007

\section{Referências}

ANTUNES, A. Cabimento. 2003. (música).

CASTRO, E.D.et al. Formação em Terapia Ocupacional na interface das Artes e da Saúde: a experiência do PACTO. Rev. Ter. Ocup. Univ. São Paulo, v.20, n.3, 2009. Disponível em: <http://www. revistasusp.sibi.usp.br/ scielo.php?script $=$ sci_arttext\&pid $=$ S1415-91042009000300003\&lng $=$ pt\&nrm $=$ iso $>$. Acesso em: 9 ago. 2011.

CASTRO, E.D.; INFORSATO, E.A. Programa de Estágio - $1^{\circ}$ semestre de 2007. Terapia Ocupacional e as ações na interface Arte e Saúde. São Paulo: Curso de Graduação em Terapia Ocupacional, FMUSP, 2007.

CLARK, L. Carta a Mario Pedrosa, 1967. In: ROLNIK, S. (Org.). Lygia Clark e o híbrido arte/clínica. São Paulo, 1996. Disponível em: <http://caosmose.net/ suelyrolnik/pdf/Artecli.pdf>. Acesso em: 6 maio 2011.

DUARTE, R.E.S.T. Criando cartografias de criação. 2008. Monografia (Conclusão de curso) - Curso de Graduação em Terapia Ocupacional, Faculdade de Medicina de São Paulo, São Paulo. 2008.

LIMA, E.M.F.A. et al. Ação e criação na interface das artes e da saúde. Rev. Ter.

Ocup. Univ. São Paulo, v.20, n.3, 2009. Disponível em: <http://

www.revistasusp.sibi.usp.br/scielo.php? script $=$ sci_arttext\&pid $=\mathrm{S} 1415-$

91042009000300002\&lng =pt\&nrm=iso > . Acesso em: 9 ago. 2011.

LISPECTOR, C. Um sopro de vida: pulsações. Rio de Janeiro: Rocco, 1999.

PELBART, P. Da clausura do fora ao fora da clausura. São Paulo: Brasiliense, 1989. 